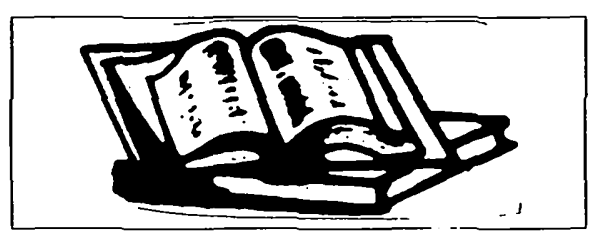

Las élites de la administración estatal (1982-1991). Estudio general y pautas de reclutamiento

ParRado Dírz, Salvador. Edición del Instituto Andaluz de Administración Pública. 1996. Sevilla.

La aproximación científica que Salvador Parrado hace a las élites de la Administración española es un interesante y certero acercamiento al mundo de los altos funcionarios españoles, así como a una parte de quienes en los últimos años han desempenaado cargos de relevancia en la Administración General del Estado. Sigue la senda de las aportaciones que en esta materia con diferentes enfoques han realizado Julián ÁLvAREZ, C. ALBA., M. BAENA y más recientemente JIMÉNEZ ASENSIO: una labor que contribuye de forma especialmente positiva no sólo al conocimiento de nuestras élites burocráticas sino también a poner de manifiesto sus virtudes y carencias. Quizás están todavía frescas las noticias, vivas las personas $y$, sobre todo, palpitantes los argumentos para lograr una serena reflexión sobre este tema, pero este hecho no consigue sino incrementar el interés por un estudio de esta naturaleza.

De alguna forma, para quienes han sido objetos de estudio, ver reflejadas ciertas ideas, algunos comportamientos e incluso estrategias no deja de ser halagador, empero, en ocasiones, puedan constituir incluso sorpresas sonrojantes, por cuanto podría haberse considerado que tales formas de actuación corporativa únicamente estaban en el secreto, en el arcano de las covachuelas, hipotéticamente inaccesibles para los estudiosos de la administración y de la ciencia política.

Procede, en mi opinión, destacar algunos logros reales de la investigación y de las pautas metodológicas utilizadas por el profesor PaRRADo (a quien, por cierto, la editorial ha olvidado incluir en la portada del libro). El primero, quizás no el principal, pero de indicación necesaria, es la certera delimitación, definición incluida, entre puestos funcionariales, en consecuencia sólo susceptibles de ser provistos entre funcionarios públicos, y puestos de carácter politico. Frente a tantos autores que en los últimos años, algunos de ellos, lamentablemente, considerados expertos, han clamado por la necesidad de la eliminación absoluta de la provisión de puestos por el sistema de libre designación a causa de la llamada politización, el autor con claridad meridiana distingue, después de analizar la posición de cada una de estas dos categorías y su peso relativo en la estructura de la Administración. Afirma, en consecuencia, que no considera que los puestos de libre designación cubiertos por funcionarios sean puestos políicos: no lo son ni por su contenido, ni por su forma de provisión o selección de candidatos.

En su momento, recuérdense años 198388 , casi ningún autor se hubiera atrevido a señalar verdad tan prístina, entonces sólo aceptada en los cenáculos de los altos funcionarios: los puestos de libre designación deben ser cubiertos por funcionarios públicos que reúnan las características del puesto de trabajo requerido. Produce cierta satisfacción que la doctrina, o al menos la investigación que el autor ha desarrollado, parta de supuestos científ$\cos y$, en este caso, no mediatizados. En cierta medida, el autor parece compartir la tan extendida idea entre los altos funcionarios de que la libre designación aunque, en ocasiones, es evidente trampolín de ambiciosos, cuyas habilidades directivas no se corresponden con el coyuntural nombramiento, es también sistema deseado para la formación de equipos o colaboradores cercanos, no sólo de los altos responsables políicos, sino de más modestos directivos de la organización burocrática.

La distinción entre unos puestos y otros es un debate ya con algunas páginas escritas y tiene mucho que ver incluso con los orígenes del Derecho Administrativo español. Muy recientemente, Manuel Arenilla lo ha recordado en un interesante artículo sobre Alejandro OuVÁN, citando al propio maestro •Desde el pensamiento impulsivo del Gobierno hasta la acción administrativa no media distancia apreciable: el Gobierno y la alta Administración se tocan y se confunden a la vista. Desde entonces han pasado algunos años y numerosos estudiosos han escrito sobre el asunto pero, aunque algunos pasos se han avanzado, la inevitable zona gris continúa siendo objeto de debate.

El propio autor del estudio que comentamos, después de numerosas vueltas para distinguir entre altos cargos y Directores Generales (cuya diferenciación permite jugosos matices y no total coincidencia con otros autores) acaba por concluir que en el período socialista, en el nombramiento de los ministros, da la impresión que se ha preferido personas que conocieran los entresijos de la burocracia estatal antes que parlamentarios versados en las tareas políticas".

Igualmente, estudia con profundidad la pertenencia o no al partido políico gobernante de los altos cargos de la Administración del Estado, señalando, entre 
otras conclusiones, las diferencias en el tre los altos cargos (Ministros, Secretarios grado de afiliación política existentes en- de Estado, Subsecretarios) y Directores
Generales, según puede comprobarse en el cuadro adjunto.

La afiliación a un partido politico seguin el rango (1982-1991)

\begin{tabular}{|lcccccc|}
\hline \multirow{2}{*}{$\begin{array}{c}\text { Rango } \\
\text { Partido Politico }\end{array}$} & Alto Cargo & \multicolumn{2}{c}{ Director General } & Total \\
\hline & $\mathbf{n}$ & $\%$ & $\mathbf{n}$ & $\%$ & $\mathbf{n}$ & $\%$ \\
\hline Ninguno & 39 & 26,5 & 93 & 18,0 & 132 & 19,9 \\
PSOE & 73 & 49,7 & 156 & 30,2 & 229 & 34,5 \\
Oưo & 3 & 2,0 & 11 & 2,1 & 14 & 2,1 \\
Sin información & 30 & 20,4 & 259 & 50,1 & 289 & 43,5 \\
$n=100 \%$ & 147 & & 517 & & 664 & \\
\hline
\end{tabular}

Fuente: Véase el apdo. 9.2. Elaboración propia.

Alto Cargo:

Secretario de Estado

Subsecretario

Secretario General
Director General:

Director General

Secretario General Técnico

Jefe Gabinete Ministro

Presidente de un Organismo Autónomo
Aunque las ausencias de datos son en algunos de los supuestos considerables, como el mismo autor reconoce, las aproximaciones mantienen el interés: mantenimiento del pudor a la declaración de pertenencia en algún caso, predominio de los sin partido, mayor afiliación en la cúspide de la pirámide ...

Otra característica sobresaliente del trabajo que se comenta se refiere a las afirmaciones del autor en relación con las modificaciones de las élites directivas realizadas por el Gobierno socialista de forma inmediata desde su incorporación al Gobierno. Después de pasar revista al proceso de modificación de estas élites como consecuencia del fin del período franquista que, en líneas generales, supuso la transformación de una buena parte de las élites franquistas y la incorporación de una nueva savia sin ningún tipo de relación con el régimen anterior, se extiende PARRADO en el periodo socialista y en particular en demostrar que el cambio de gobierno trajo consigo una renovación casi total de las élites politico-administrativas (279). Afirma además el autor que una sustitución casi completa de las élites político-administrativas en un tiempo tan breve - unos cinco meses- no se había experimentado ni durante el régimen franquista ni durante el período de transición-UCD.

Probablemente, y PARRaDo se esfuerza en demostrarlo, así fuera, pero quedan algunos matices que poner de manifiesto aunque sólo sea para puntualizar que buena parte de las élites político-administrativas sustituidas (en particular la mayoría de los pertenecientes a los altos cuerpos de funcionarios) consiguieron una recolocación inmediata o al menos tras pocos meses de descanso obligado. Factores estructurales (la expansión administrativa del Estado del Bienestar, según el autor, la Administración es abora ocho veces mayor que en los últimos años del franquismo, la ausencia de compromiso político anterior de buena parte de estas élites) y coyunturales (el traspaso a las Comunidades Autónomas no afecta a la dimensión de la Administración Central, la incorporación a la Comunidad Europea potencia los perfiles de experien- cia y técnicos en los altos funcionarios, la ausencia de cuadros suficientes por parte del partido gobernante...) permitieron, pues, que en la gran mayoría de los casos, los miembros de las élites políicoadministrativas, en particular los que habían accedido a cargos de Director General o equivalente, continuaran desempeñando similares cargos aunque, probablemente, en otro Ministerio u organismo. Aquí juegan especial papel los cuerpos como con cierta soma afirma PARRADO ... el funcionario ba podido comprender que importa más pertenecer a un cuerpo burocrático fuerte, que esgrimir el carné del partido en el camino bacia la cúpula.

Otro factor, éste relacionado con la pura técnica de manejo de recursos humanos, permitió una transición menos dolorosa: la flexibilidad establecida para el paso de los funcionarios desde unos Ministerios a otros, en particular en lo que se refería a los altos funcionarios. El incremento de las estructuras administrativas del período permitió, además, la permanencia en puestos similares de la inmensa mayoría de los funcionarios que 
La condición de funcionario según el rango (1982-1991)

\begin{tabular}{|c|c|c|c|c|c|c|}
\hline \multirow{2}{*}{$\begin{array}{c}\text { Cargo } \\
\text { Condición }\end{array}$} & \multicolumn{2}{|c|}{ Alto Cargo } & \multicolumn{2}{|c|}{ Director General } & \multicolumn{2}{|c|}{ Total } \\
\hline & n & $\%$ & $\mathbf{n}$ & $\%$ & n & $\%$ \\
\hline Funcionario & 96 & 66,2 & 406 & 78,2 & 502 & 75,6 \\
\hline No funcionario & 49 & 33,8 & 113 & 21,8 & 162 & 24,4 \\
\hline$n=100 \%$ & 145 & & 519 & & 664 & \\
\hline
\end{tabular}

Fuente: Véase el apdo. 9.2. Elaboración propia.

Alto Cargo:

Director General:

Secretario de Estado

Director General

Subsecretario

Secretario General

Secretario General Técnico

Jefe Gabinete Ministro

Presidente de un Organismo Autónomo

se encontraban en la cúspide de la carrera profesional: los subdirectores generales.

En resumen, una aportación al estudio de las élites político-administrativas que, aun susceptible de otros enfoques que logren completar este trabajo, no dejará de ser referencia obligada para quien esrudie estos temas: por ejemplo, las modificaciones realizadas por el actual gobierno en las élites político-administrativas, probablemente de mayor calado, ya que la coyuntura es de reducción administrativa y de restricción en los cambios interdepartamentales.

Francisco VeLázQuez López Cuerpo Superior de Administrativos Civiles del Estado

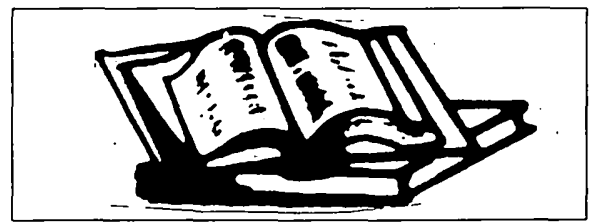

\section{La formación de la politica} económica

ARIas, Xosé Carlos. Editorial Civitas, Madrid, 1996.

La economía, y en esto comparte rasgos con la biología, es habitualmente descri- ta, sobre todo por académicos que pueblan territorios colindantes, como una ciencia imperialista (HIRSHLEIFER, 1985) que gusta de imponer a los demás sus metodologías y enfoques de estudio. La ciencia económica estaría de acuerdo con esta visión enzarzada en una lucha continua por incrementar su territorio a costa de sus metodológicamente más débiles vecinos, politólogos y sociólogos (Lejonhufvud, 1982), que verían su terreno cada vez más reducido, a buena parte de su población colonizada, sentada en la misma mesa compartiendo las aparentemente deliciosas viandas traídas de las tierras del colonizador (ALMOND, 1988) y asombrada por los relucientes abalorios del invasor, que parecen traer a estos atrasados pueblos promesas inagotables de prosperidad y avance científico (BuCHANAN, MCCormick, Tollison, 1984), y a sus viejas creencias e ídolos, relegadas a los ancianos de la tribu demasiado viejos para adaptarse a los cambios, siendo sustituidas paulatinamente por la religión del colonizador adaptada superficialmente a los rituales nativos (MUELLER, 1984).

Por otro lado, el invasor acostumbraba a despreciar las viejas técnicas del indigena y era poco receptivo a su ancestral sabiduría.

Pero al cabo de un tiempo la colonización dio sus frutos. Los politólogos, manteniendo muchas de sus viejas y tradicionales costumbres, incorporaron, tras un período de adaptación, las tecnologias del invasor logrando poco a poco productos de calidad perfectamente equiparable a los de la metrópoli, productos que se fueron introduciendo paulatinamente en sus selectivos mercados.

Uno de estos productos fruto de la vieja artesanía politológica y de las nuevas técnicas analíticas de la economía es el análisis de políticas públicas, que recoge muchos de los temas de interés de la vieja ciencia política (partidos, grupos de interés, procesos electorales) a los que atribuye pautas de racionalidad económica en su comportamiento, pero vistos desde una perspectiva sin tradición en la ciencia política, pero muy común en la economía: la perspectiva de las políticas. Esta perspectiva estudia las dinámicas políticas y económicas no desde el punto de vista del comportamiento institucional (parlamentos, gobiernos, procesos electorales) sino desde el punto de vista desagregado del producto de este comportamiento institucional, esto es, de las políticas o actuaciones concretas de la autoridad pública sobre algún aspecto de la vida económica o social. La economía política había procedido desde hace mucho tiempo a este estudio desagregado, al estudiar los impactos concretos de 
la formulación de las distintas intervenciones del Estado en la vida económica. Las políticas de renta, las políticas fiscales, las políticas monetarias han sido estudiadas en profundidad por los economistas desde la publicación de la Teoría general de KeYNES (KeYNES, 1984), que sentó las bases teóricas para la intervención estatal, vía políticas públicas, en la vida económica.

Sin embargo, y a pesar de su dilatada historia, al proceder al estudio de las políticas económicas no se acostumbraba a observar los condicionamientos políticos, esto es, el juego de actores, dotados en distintos grados cada uno de ellos con recursos políico-económicos y organizativos, con intereses diversos presionando de muy diversas formas para ver atendidos sus intereses por los responsables formales de la elaboración de políticas.

Por parte de los politólogos tampoco se había demostrado excesivo interés, y sigue hasta el momento sin demostrarse, por las políticas económicas. En primer lugar, porque el análisis de políticas públicas cuenta aún con relativamente poco tiempo de vida, la mayoría de sus trabajos seminales son de finales de los años 60 (AgurlaR, 1992), y sus intereses iniciales orientados a las políticas sociales por encontrarse ahí un terreno abonado por cuantiosos recursos materiales para la investigación. En segundo lugar, el lenguaje críptico usado por los economistas, bien por usar como KeYNeS, padre de la moderna política económica, una jerga cabalística sólo comprensible por los brujos de la tribu de los econos, bien por recurrir a lenguajes matemáticos que los econos toman de tribus a las que ellos rinden vasallaje como los matematos, hacen que al pobre polito le sea muy difícil seguir los razonamientos de sus vecinos, razonamientos que, por otra parte, en muchas ocasiones no tienen nada de complicado.

Escrito con la voluntad manifiesta de superar la incomunicación que existe entre estas dos tribus, obligadas pese a todo a entenderse, el libro del profesor ArIAS resulta extraordinariamente útil a aquellos, como el que escribe estas líneas, que se ven obligados a explicar las actuaciones del gobiemo en el área económica, área que afecta a muchas de las más relevantes, para el decisor y para los afectados, y controvertidas decisiones que tienen que afrontar los políticos en su cotidiano discurrir.

La formulación de una política económica es, como bien nos señala el autor, en esencia similar a la elaboración de cualquier otro tipo de política pública. Sigue un proceso (Mény y ThOenig, 1992) más o menos consciente de definición del problema, pasa a través de una serie de filtros políticos institucionales que deciden su entrada o no en la agenda del decisor, y suscita un conflicto, de mayor o menor intensidad según sea el caso entre los actores a quienes afecta, a la hora de su formulación y legitimación por la instancia correspondiente. La economía política, o ciencia de la política económica como gusta de definirla el profesor ARias, no solía considerar, tras decidir la intervención pública en determinada área, los aspectos políitcos que se derivaban de dicha intervención; es decir, quién se veía beneficiado o periudicado por dicha medida, en qué cantidad y, sobre todo, con qué recursos económicos, políticos u organizativos contaban estos afectados para acelerar, mantener, modificar o paralizar las actuaciones del gobierno que les afectasen. Más bien se limitaba a ofrecer información, más o menos útil para el decisor sobre las consecuencias que para las variables agregadas tenían dichas medidas, sin apuntar las implicaciones que para el gobermante, encargado de tomar la decisión, tenían dichas medidas, consecuencias éstas que sí son analizadas en este libro.

El libro aporta, sobre todo para el público hispano, dos interesantes aportaciones que lo capacitan extraordinariamente para ser utilizado como libro introductorio no sólo en las Facultades de Ciencias Económicas sino también en las Facultades de Ciencias Políticas. En primer lugar, podemos apuntar la integración en un solo volumen de los dos grandes conjuntos de estudios de lo que en las lenguas romances se denomina análisis de políticas. Por una parte, el autor se refiere a los principios de la economía del bienestar así como los modelos óptimos de toma de decisión, que constituyen lo que que se entiende en inglés como Policy Analysis o conjunto de técnicas analíticas que buscan mejorar la racionalidad en el proceso político. Por otra parte, el autor integra estas técnicas en el estudio del proceso de formulación de politicas públicas, conocido en inglés como Public Policy Analysis, que busca entender los procesos, primordialmente políticos, que contribuyen a la configuración de las políticas públicas, en este caso políticas económicas. La integración de estas dos ramas del análisis de políticas permite al público no familiarizado entender claramente los condicionantes técnicos y políticos que influyen a la hora de elaborar estas políticas.

En segundo lugar el libro de Xosé Carlos ARIAs incorpora al análisis el papel que juegan las ideas, y no sólo las económicas, en el proceso de formación de la política económica. Los grandes teóricos del análisis de políticas públicas, con algunas excepciones (DroR, 1989), acostumbran a centrar sus análisis en las relaciones, conflictuales o cooperativas, de los actores que intervienen en la elaboración de políticas públicas, descuidando el papel que las ideas que estos actores tienen acerca de los fenómenos económicos influyen en su comportamiento. No es lo mismo creer, por ejemplo, que la culpa del subdesarrollo la tienen las políticas neoliberales, por ejemplo, que creer que la culpa la tiene la carencia de dichas políticas. Las políticas económicas que se seguirán diferirán enormemente según los decisores asuman una u otra suposición.

A ARIAS sin embargo sí le interesa el papel de las ideas en el proceso político (ARIAS, 1996) y de hecho las incorpora, en el papel que se merecen, al estudio del proceso político. Para el autor las ideas modelan los intereses y a su vez éstos contri- 
buyen a modelar las ideas. Las ideas juegan además un claro papel legitimador de las políticas en curso. El caso de las ideas keynesianas usadas como elemento legitimador de las políticas económicas ya emprendidas por Roosevelt es un ejemplo, del que nuestro autor parece gustar bastante, muy elocuente de lo dicho.

El libro aun resultando extremadamente útil tiene a mi ver una carencia: el que no considera la implementación de las políticas económicas, aspecto éste que sería de extraordinario interés que fuera abordado en sucesivos trabajos del autor. En efecto, muchas políticas económicas perfectamente diseñadas fracasan en su puesta en práctica por muchas razones. Bien porque no hay un interés real por parte de algún actor clave en que se cumplan, bien porque las expectativas que los actores tienen de estas políticas no se corresponden con las intenciones perseguidas por los formuladores de la misma. Las expectativas, ideas y creencias juegan aquí también, lo mismo que los intereses organizados, un importantísimo papel, que puede determinar el éxito o el fracaso de una iniciativa de política económica. La políica no acaba en su formulación, y éste es un error en el que incurren aún muchos responsables de la formulación de políticas económicas, pero que los analistas rigurosos no deben obviar. Esperamos, pues, con agrado la continuación de este, por lo demás espléndido, libro.

Miguel Anxo Bastos BoubeTA Facultade de Ciencias Políticas e Sociais Universidade de Santiago de Compostela

\section{REFERENCIAS}

agullar Vilianueva, Luis F. (comp.) (1992), El Estudio de las Politicas Puiblicas, Miguel Ángel Porrúa editor, México.

AlmoD, Gabriel A. (1988), separate Tables: School and Sects in Political Science. en PS: Political Science and Politics, vol. XXI, n. 4, Otoño, pp. 828-842.

ARIAS, Xosé Carlos (1996), •Ideas, Intereses y Política Económican en Claves de Razón Práctica, n. 62, Mayo.

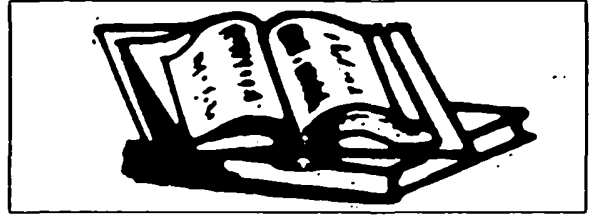

\section{La crisis de la inteligencia. Ensayo sobre la incapacidad de las élites para reformarse}

CrozIER, Michel con Twurtre, Bruno. Instituto Nacional de Administración Pública y Boletín Oficial del Estado, Madrid, 1996. 153 págs.

La obra que recensionamos afronta un problema universal que, sin embargo, dentro de los países avanzados, presenta en Francia especiales singularidades por las particularidades del sistema de selección y de formación de sus élites tecnocráticas: la crisis moral e intelectual que manifiestan las élites para hacer frente a un complejo mundo lleno de incertidumbres, a las que no pueden ofrecer respuestas certeras y útiles desde sus esquemas y su lenguaje estereotipado y tecnocrático, acostumbradas como están a considerar que los problemas requieren soluciones y respuestas "ingeniosas" u "originales", ofrecidas desde la superioridad de su formación y de su status, sin ser capaces de establecer una relación interactiva con los destinatarios de sus decisiones y, con frecuencia, careciendo de la menor experiencia vital directa sobre los ámbitos en los que proyectan sus responsabilidades profesionales desde el centro.

El autor de la obra, Michel Crozier, es un viejo y prestigioso conocido de los profesionales y estudiosos de la Ciencia de la Administración en nuestro país. Investigador, profesor de Sociología y consultor, ha sido docente en diversas prestigiosas Universidades francesas y norteamericanas (Politécnica de París - Nanterre-, Harvard y California, entre otras), siendo uno de los protagonistas más activos de un amplio movimiento desarrollado en numerosos países occidentales, partiendo de la sociología y de la psicosociología americanas y de las nuevas concepciones de la gestión que se han derivado de ellas. Fue el fundador y director durante veinte años del Centro de Sociología de las Organizaciones y del DEA de Sociología del Instituto de Estudios Políticos de París. Es autor de nüumerosas obras -algunas de ellas considerada ya verdaderos clásicos de la ciencia administrativa-, entre las que pueden destacarse Le Pbénomène Bureaucratique (1964), La société bloquée (1970), L'Acteur et le système (en colaboración con E. Friedberg, 1977), On ne change pas la société par Décret (1979) ', Le Mal Américain (1980), État modeste, Etat moderne. Stratégies pour un autre changement (1987) ${ }^{2}$, Comment réformer l'État? trois pays, trois stratégies: Suède, Japon, Etats-Unis (1988) ${ }^{3}$, y L'Entreprise à l'écoute (1989).

En esta obra colabora con CROzIER el periodista y asesor de comunicación Bruno TIllietTe, coautor, con Bob AuBreY, del libro Savoir faire Savoir (1990).

La obra que comentamos se estructura en dos partes bien diferenciadas y de casi idéntica extensión. La primera de ellas, fruto exclusivo de Michel Crozier, afronta con la estructura típica de un ensayo dividido por capítulos un análisis de lo que el autor denomina $\boldsymbol{E} \boldsymbol{I}$ mal de las élites: (tal es su rúbrica), abordando la gran tragedia de la confusa sociedad francesa de los años noventa: la pérdida casi total de confianza en sus élites, que a su vez viven en una profunda impotencia, víctimas de su propia formación y de su lenguaje estereotipado, incapaces de reconocer las críticas hacia su ineficacia y culpando a la propia sociedad que

\footnotetext{
${ }^{1}$ Existe versión espanoola de la segunda edición francesa (1982), con el útulo de No se cambia la sociedad por decreto, traducción e introducción para espanoles y latinoamericanos de Joan Prats i Català; INAP, Madrid, 1984.

${ }^{2}$ Existe versión española: Estado modesto, Estado moderno. Estrategia para el cambio, traducción de Jorge Ferreiro; FCE, México, 1989.

${ }^{3}$ También existe versión española de esta obra: Cómo reformar el Estado. Tres paises, tres estrategias: Suecia, Japón, Estados Unidas, traducción de Rosa Cusminsky de Cendrero; FCE, México, 1992.
} 
han de regir de su incapacidad para llevar adelante cambios efectivos. Una tragedia que se agrava por el hecho de que nadie se atreve a reprocharles la responsabilidad de la rigidez y la compartimentación que paraliza las iniciativas, cuya razón se encuentra en la cúspide del Estado, de las Administraciones, y en el sistema de grandes escuelas y de grandes cuerpos estatales.

Este desconcierto obedece, esencialmente, a un déficit de einteligencian: interviniendo en todas las cuestiones y en todo momento, las élites y los dirigentes franceses impiden a los ciudadanos adaptarse, al suplantarlos. Así, en el marco de las empresas privadas se detecta una actitud regresiva en las élites, recentralizando de hecho, ahogando las iniciativas, y privando a las personas $y$, sobre todo, a los directivos, de la imprescindible capacidad de innovación y de desarrollo cualitativo. $Y$ otro tanto se produce en el ámbito de las instituciones públicas, con un retorno al Estado regulador y a la idea del "prefecto-árbitro".

En este contexto, el efecto es el de la desmoralización de las personas, que se ven privadas de un contexto deseable de desarrollo de la responsabilidad y de la cooperación, agravado por la actitud conservadora y temerosa de la mayoría de los políticos de todos los signos.

Detrás de todo ello late, según el autor, la einteligencia a la francesan, inadaptada al mundo presente $y$, por lo tanto, inútil y regresiva, bloqueando el sistema político-administrativo y, dentro del mismo, a sus élites. Unas élites que el autor no pretende sustituir $-\mathrm{y}$ cuyos valores intelectuales tampoco niega - sino readaptar para aprovechar su derrochado talento, mediante un método intelectual y una estrategia de reconquista.

A partir de esta idea, la primera parte de la obra trata de una serie de aspectos esenciales para la corrección de ese -mal de las élites. Así, se cuestiona abiertamente el sistema de formación de las mismas que, a través del modo de razo- namiento que ha debido interiorizarse por los alumnos para superar los exámenes y oposiciones, impone una lógica muy peculiar que constituye la principal característica de su personalidad intelectual, según la cual la búsqueda de la solución predomina sobre la construcción del problema. En las grandes escuelas administrativas francesas (la Escuela Politécnica, la Escuela Nacional de Administración - la célebre ENA-) la cultura se focaliza en la utilidad de las pruebas que determinarán el éxito, la oposición de acceso y la calificación final de los alumnos, de forma tal que el contenido de la enseñanza pierde importancia en sí mismo, al ser, más que un instrumento de dominio del entorno en el marco de la preparación para una profesión, un medio para superar los aspectos aleatorios de las técnicas de clasificación de los alumnos. Con ello se estimula •lo seguro", de manera que todo lo que resulte vago, abierto o aventurado se rechaza tanto por los alumnos como por las instituciones.

A ello debe unirse una formación que tiende a establecer una fuerte relación entre una orientación enciclopédica, la preferencia por soluciones elegantes. y un molde de lógica conformista difícilmente superable, que se forja antes de tener cualquier experiencia práctica, y se acentúa por la circunstancia -gravísima en este contexto- del acceso con demasiada rapidez a puestos directivos aislados de la realidad operativa, lo que acentúa la tendencia a encontrar la legitimación en su formación y en su capacidad para aportar soluciones brillantes a los problemas que destaquen los medios de comunicación (problemas que son afrontados con menos energía que sus teóricas soluciones, con una notoria tendencia a la abstracción), sin contacto, en general, con la vida real de los subordinados y del público al que deben servir.

Un problema que, como se ha señalado, no pretende superar CROZIER por la vía de la sustitución de las élites, que considera necesarias en toda sociedad, sino por el camino de trabajar sobre la inteligencia, aportando un modelo intelectual que demuestre su superioridad y que puedan asumir por tal razón.

Pero Crozier va más allá del cuestionamiento exclusivo del sistema de selección y formación de las élites administrativas, planteando las deficiencias del sistema educativo nacional francés. Un sistema cuya reforma ha sido abordada en numerosas ocasiones sin que ningún intento haya fructificado satisfactoriamente, y que, en opinión del autor, a pesar de su relativa excelencian en lo que se refiere al nivel de instrucción que consigue desde perspectivas clásicas, debería superar esencialmente su incapacidad para orientar su acción hacia la eficacia personal de los individuos en un entorno cada vez más relacional, en el paso de un mundo de la obediencia a otro de la responsabilidad. En definitiva, la educación debe orientarse esencialmente hacia el aprendizaje de la libertad, entendida como libertad de elección, además de la tradicional e insustituible libertad como valor moral y político.

La escuela debe, además, enseñar a enfrentarse a la complejidad del mundo moderno, tanto en lo que respecta al mundo de la ciencia y de la técnica como en lo que se refiere a los problemas de la vida en sociedad, para dominarla y reducirla. Y finalmente, en un mundo crecientemente relacional, hace falta desarrollar la lógica de la cooperación, y para ello la escuela debe enseñar a escuchar, no sólo a los ensenantes, sino también entre los alumnos, aprendiendo a debatir con tolerancia.

Precisamente es la falta de escucha la mayor queja que formulan los franceses frente a sus élites y gobernantes. Algo que no se soluciona con sondeos de opinión, ya que éstos se elaboran desde la lógica de quien los prepara. La escucha se concibe como un procedimiento interactivo, que permite a los ejecutores hablar a los dirigentes y a éstos hablar a aquéllos a su vez, para ser oídos. Se des- 
taca por CROzIER el aspecto cualitativo que debe presidir el proceso, huyendo del fácil recurso exclusivo o preferente a las técnicas cuantitativas como las encuestas y sondeos para afrontar la solución a este problema. En este sentido, el autor resalta, por un lado, la inutilidad de la manipulación en el proceso de escucha - pues se acaba volviendo contra quien la practica-, y, por otro, la crisis de los mecanismos y organizaciones tradicionales de representación de intereses. En su opinión, estas organizaciones no pueden pretender monopolizar la representación de todos los temas, ya que su capacidad representativa actual se limita a ciertas "minorías activas", que reflejan de una manera cada vez más difuminada la realidad social que viven los que han delegado en ellas, debiendo asumir funciones más de enlace y de escucha para superar el bloqueo real que produce su pretensión globalizadora. En definitiva, el diálogo social sólo puede restablecerse mediante la escucha, la apertura y el fin de los monopolios de representación.

Es así como Crozier llega al planteamiento del paso de una democracia de acceso a otra de deliberación, superando el modelo clásico francés, en el que el Estado aparece como el único depositario y guardián del interés común, lo que le convierte, de facto, en el único árbitro aceptable y posible $-\mathrm{y}$, por lo tanto, obligado- de todos los conflictos. Una idea muy propia de la cultura política francesa. Frente a ello, Crozier propone el uso de las nuevas formas de descentralización, tanto económicas como politicas, que, al favorecer la autonomía de pequeñas unidades operativas, permiten que las personas y los grupos tengan conciencia del resultado de sus actividades comunes, que se desarrollan a través de procesos de poder e intercambio, lo que permite afrontar de otra manera los problemas, mediante la búsqueda y consecución del consenso, que es algo que no se adquiere sin más, sino precisamente como consecuencia de una cooperación eficaz que requiere esfuerzos.
Por ello se plantea la necesidad de transformar el sistema político-administrativo francés, basado en una noción de democracia de acceso, en la que lo que importa es tener acceso a quien adopta las decisiones, en el marco de una cadena jerárquica que se caracteriza por un sistema burocrático, con grados superpuestos y cadenas de procedimientos que no sólo no estimula la innovación, sino que la paraliza. Una noción detrás de la que late la idea de que existe un -interés general. por encima de loś ciudadanos, encarnado por unos servidores especiales, precisamente los altos funcionarios cuidadosamente seleccionados y educados para ser sus guardianes. Evidentemente, tal idea está destinada a chocar directamente con la de que mediante la deliberación se puede alcanzar el consenso. La superación de esa situación exige una inversión masiva en el desarrollo del conocimiento de los sistemas humanos reales, en vez de seguir con la ilusión de que se dirige en nombre del supuesto interés general.

Finalmente, en la primera parte de la obra se aborda la necesidad de priorizar la atención de los problemas sobre la consideración de las soluciones. CROzIER plantea que, con frecuencia, resulta tentador razonar a la inversa y adaptar el problema que se enfrenta a la solución definida de antemano, con el riesgo de olvidar el problema real. Y esta aparentemente paradójica situación responde a varias causas. Entre ellas, el autor destaca la tradicional tendencia francesa a considerar al decisor como un superhombre que debe tener respuesta para todo, ya que en caso contrario se le considera incapaz, así como al desprecio al trabajo colegiado y a las comisiones. Además, debido a las presiones mediáticas y a las urgencias, existe todo un grupo de "agentes de soluciones" que se dedican a elaborar soluciones que no tienen una relación directa con los problemas prácticos, soluciones en buena medida determinadas por las modas y las corrientes dominantes, de manera que lo brillante y lo elegante tiende a imponerse por encima de consideraciones pragmáticas.

Crozier considera esencial, en la superación de tal tendencia, la corrección de una característica que se da tanto en el sector público como en el privado: las élites han ascendido muy jóvenes y no han tenido la oportunidad de conocer el fracaso y de sacar fruto de sus experiencias. Una trayectoria más lenta, con permanencia dilatada en puestos secundarios, aporta la experiencia necesaria para madurar y para aprender a razonar de una manera que les permita afrontar los problemas que surgen en complejas interacciones que desbordan los esquemas jerárquicos tradicionales.

La segunda parte de la obra lleva por rúbrica "Invertir en el cambio" y, a diferencia de la anterior, adopta la forma de una entrevista en la que Michel Crozier responde a las cuestiones que le plantea su colaborador Bruno Tiluette. Para CroZIER invertir en el cambio consiste en crear las condiciones para que los agentes operativos descubran que resultaría beneficioso comportarse de otro modo, no sólo para el interés de sus operaciones y del conjunto que forman, sino también para ellos mismos, lo que implica confiar en ellos y crear la confianza para pasar de un círculo vicioso a otro virtuoso. Un cambio en el que el objetivo no consiste en reducir el papel del Estado, sino en otorgarle otro papel: no ya el de dirigir una sociedad reacia, sino el de ayudarla a transformarse, que considera más excitante y difícil que aquél. $Y$ para ello indica que pueden usarse tres grandes palancas: la intervención directa -indispensable cuando un sector se halla en crisis aguda-; la preparación de los dirigentes y ejecutivos para un nuevo modo de razonar; y la inversión más general en la transformación de las instituciones que constituyen el armazón intelectual y moral del sistema políticoadministrativo. 
A partir de estas ideas centrales, CROZIER expone detalladamente en esta segunda parte sus experiencias e ideas en estos tres campos, con el dinamismo propio de la forma de entrevista. Así, en el ámbito de la intervención directa, explica su participación como consultor en diversas experiencias planteadas en sectores concretos en crisis, como la Société National des Chemins de Fer (SNCF), en Air France o el Ministerio de Obras Públicas francés, planteando la posibilidad de aplicar las lecciones extraídas en sectores como la enseñanza, la sanidad, la lucha contra el desempleo e, incluso, las empresas privadas.

Especialmente interesante resulta la exposición del nuevo razonamiento que propugna Crozier. Lo caracteriza como un razonamiento en cuatro tiempos. El primer tiempo es el razonamiento pluralista práctico basado en el concepto de racionalidad limitada, que parte de la idea de que el ser humano no es capaz de poseer un razonamiento óptimo que le permita encontrar la solución sideal" a un problema, sino que opta por la primera solución satisfactoria que descubre de acuerdo con unos criterios inconscientes de racionalidad que se establecen sobre la base de su entorno de referencia y de los intereses que persigue; algo que congenia con la naturaleza oportunista del animal humano, capaz de percibir una ocasión nueva y de explotarla. El segundo tiempo consiste en una concepción del poder que no se basa en la posesión, sino en la relación, ya que el poder sólo se entiende dentro de ésta, lo que permite ver la realidad de otra forma, especialmente en relación con el problema central de la cooperación y el conflicto: no hay cooperación sin conflicto, ni conflicto sin cooperación. El tercer tiempo se refiere a los resortes de la construcción de una organización, ya que al estar éstas basadas en juego de poder entre cierto número de personas, en función de las características de tales juegos se desprenden estrategias racionales y no racionales, de forma que tras un proceso de pruebas/errores todos los individuos acaban por descubrir qué estrategias son para ellos racionales dentro del contexto de juego. Y finalmente, el cuarto tiempo es de naturaleza metodológica, y se refiere a la comprensión de estos juegos, que se realiza a partir de diálogos en los que se pregunte a las personas cómo resuelven sus problemas cotidianamente, y no directamente cuáles son los juegos que se dan en el interior de su empresa o institución, ya que no tienen clara conciencia de ellos.

En definitiva, lo que se rechaza es un modelo de racionalidad absoluta, ya que con el mismo todo el mundo aparece como irracional, puesto que todos adoptan sus decisiones en el contexto de la racionalidad de su juego exclusivamente. Y a esta conclusión llega Crozier tras una dilatada experiencia personal y mediante el aprendizaje obtenido de numerosos fracasos, tanto vitales como en los campos de la investigación y la docencia. Experiencia que le indica la necesidad de superar el modelo pedagógico prescriptivo dominante, en el que el alumno se limite a aprender reproduciendo los preceptos que se le han inculcado, tarea que reconoce como lenta y difícil: se necesita tiempo para cambiar y buscar el resultado rápido es el mejor camino para no alcanzar el éxito. Como senala el propio CROzIer, •es mucho más dificil bacer fuerza sobre un sistema de pensamiento que sobre una estructura 0 incluso más que bacer la revolución.

Para esta transformación del pensamiento Crozier apuesta por crear en las grandes escuelas de funcionarios instituciones en el sentido sociológico del término, basadas en colectivos humanos lo suficientemente variados, donde se establezcan relaciones de cooperación dirigidas a la adquisición de un modo de razonar eficaz, más que hacia técnicas y métodos. Unas instituciones que no estén dedicadas exclusivamente a la formación, sino que deberían asociar tres dimensiones: la formación de los futuros dirigentes, la investigación de alto nivel en materia de políticas públicas y un centro dinamizador para el lanzamiento y seguimiento de nuevas experiencias de preparación y evaluación de las decisiones públicas. Y apuesta asimismo por un sistema que evite el derroche de recursos, en el que la selección se haga por medios más racionales que las oposiciones (informes, entrevistas), la formación inicial tenga menos importancia que la adquirida tras varios años de experiencia profesional, y se intensifique la experiencia de estudios en el extranjero. A todo esto añade expresamente su opinión de que los gabinetes ministeriales no son, seguramente, instrumentos indispensables para el funcionamiento del Estado y que suprimiéndolos desaparecería la tentación de convertirlos en una antesala política, aunque debe considerarse que esta idea se expresa desde un país en el que los gabinetes se habían hipertrofiado en sus dimensiones y funciones.

Para finalizar, Crozier destaca la necesidad de reemplazar el sistema jerárquico por la disposición a cooperar, expresando su convicción en que se avanzará indefectiblemente por este camino como una verdadera necesidad societaria, declarando expresamente su condición de humanista, cualidad que cifra en el valor del respeto hacia el otro.

En conclusión, nos encontramos ante una obra de gran interés, que aunque se centre en la problemática específica que plantean la formación, los valores y la actuación de las élites en Francia, presenta en numerosos aspectos análisis de validez general en el ámbito de las sociedades postindustriales en el que se inserta nuestro país. Ciertamente, en España se han desarrollado procesos de modemización y de descentralización política que han permitido deshacerse del modelo centralista y jerarquizado de inspiración francesa. Por ello, se ha desarrollado una amplia cultura del consenso entre los actores e instituciones del sistema político, de manera que problemas tales como el monopolio por el Estado del interés general o la necesidad de su 
exclusivo arbitraje como último valedor de tal interés se hayan superados o en curso de franca superación. Sin embargo, el análisis de Crozier sobre aspectos de las escuelas de funcionarios o de la formación de las élites y su promoción en las instituciones públicas resultan en buena medida aplicables a nuestro país. En efecto, también entre nosotros se producen algunas de las situaciones patológicas que señala CROZIER - piénsese, a título de ejemplo-, en la rápida promoción en los Ministerios de funcionarios recién ingresados con escasísima (cuando no nula) experiencia de contacto con los clientes de la Administración o conocimiento práctico de los problemas a que debe enfrentarse la Administración, o en los métodos memorísticos dominantes en nuestra Universidad (especialmente en las Facultades de Ciencias Jurídicas, aunque no exclusivamente) y en el acceso a la función pública, que sin duda imprime un método de razonamiento poco dado al adecuado tratamiento de los problemas, a la captación de los matices de la realidad, al enfrentamiento a lo borroso y a la incertidumbre, y que generan una tendencia a demostrar la brillantez personal con soluciones pretendidamente ingeniosas intelectualmente, con frecuencia desconectadas de la realidad.

La obra presenta la virtud añadida de ofrecer una lectura ágil y amena, fruto en buena medida de la cuidada traducción realizada por el gran profesional de la Ciencia de la Administración que es Koldo EChEVARría ARIZNABARRETA, a quien resulta obligado felicitar por su labor.

José Manuel Rodríguez Álvarez Universidad Autónoma de Madrid

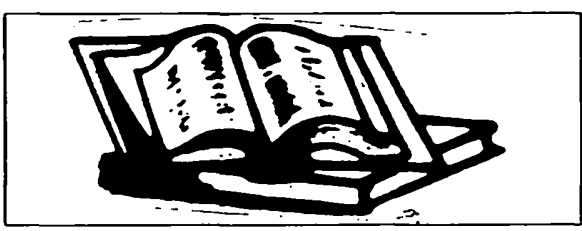

\section{La Carta Europea de la} Autonomía Local

Rodriguzz Álvarez, José Manuel. Bayer Hnos., Barcelona, 1996.

Ratificada por España el 20 de enero de 1998, y en vigor desde el primero de marzo del año siguiente, la Carta Europea de la Autonomía Local, que da título a este trabajo, adquirió la condición de ley estatal integrante del ordenamiento jurídico español en cuanto que tratado internacional autorizado por las Cortes Generales.

Que un tratado internacional venga a formar parte del cuerpo jurídico estatal no tendría mayor transcendencia si no fuera porque se está hablando de una de las piezas jurídicas vertebradoras del universo local europeo, de uno de los pilares constituyentes de un espacio democrático y autónomo, insustituible por lo referido a la prestación de servicios públicos de los ciudadanos de la Unión Europea.

En otro orden de cosas, resulta igualmente inusual que hay que esperar más de ocho años desde su entrada en vigor para poder conocer en detalle los fundamentos ideológicos, el proceso de elaboración y la capital significación práctica de este texto legal. Ésta es precisamente la empresa que aborda el profesor RoDríGUEz Álvarez y que alcanza con rigor no exento de afán divulgador.

Quizá el interés de la aparición de una monografía de estas características lo explique en parte la enorme actualidad política de la sentida necesidad de vigorizar el papel institucional que corresponde en nuestro país a los entes locales, lo que hace de la lectura de este trabajo una labor pertinente a la par que esclarecedora.
Por lo que hace a la estructura del trabajo, éste se divide en tres partes, además de las obligadas conclusiones, que encierran una lógica propia al tiempo que anuncian el capítulo siguiente.

La primera de ellas está referida al origen del principio de autonomía local entendido como defensa política, jurídica e ideológica del ámbito de actuación local. Con este empeño resulta llamativo cómo el autor da cuenta de la hábil combinación de las raíces doctrinales de la idea de autonomía local que confluyen en la Carta Europea: las teorías francesas del pouvoir municipal y de la descentralización, la teoría alemana de la Genossenschaft y el self government anglosajón, que reconocen todas ellas la existencia de un ámbito público de actuación plenamente diferenciable de cualquier forma de heteroadministración y que encuentra su materialización política en plataformas de autogobiemo encargadas de los asuntos que les son propios dentro de su correspondiente circunscripción territorial. Ahora bien, una vez reconocida la aplicabilidad directa de la Carta Europea a todos los Estados firmantes, la concreción de la autonomía local, la propiedad de los asuntos" a los que se refiere vagamente la normativa española sobre régimen local, deja de ser un concepto abstracto para cristalizar en una serie de prescripciones concretas a partir del momento en que los Estados comunitarios adoptan las medidas necesarias para su cumplimiento, lo que no implica, sin embargo, que la garantía institucional atribuida por la Carta a los entes locales europeos se identifique con estructuras organizativas concretas ni con un techo competencial determinado.

$Y$ es aquí precisamente donde parece radicar la virtualidad de la Carta Europea de la Autonomía Local: sin forzar sus principios inspiradores, consigue dotar a la idea de autonomía de un significado jurídico y político que se concretiza en las nociones de democracia y subsidiariedad. Así, la Carta Europea entiende a las entidades locales en su doble natura- 
leza de estructuras representativas y de administraciones públicas prestadoras de servicios.

No cabe duda de que la garantía de la autonomía de las entidades locales no pasa únicamente por su reconocimiento expreso en la normativa general, sino, más específicamente, por la forma de determinación de sus competencias, la naturaleza de éstas y los mecanismos de control reservados y empleados por entes políticos de ámbito territorial superior. En este sentido, ni el sistema de determinación competencial de cláusula general, propio de los países continentales, ni el de lista enumerativa, de los anglosajones, son garantía de la autonomía local si no se acompaña de medios para la prestación efectiva de servicios públicos ni, por supuesto, de instrumentos de exigencia de responsabilidad politica y gerencial.

Recogido en la segunda parte del trabajo el proceso de elaboración y el comentario detenido del contenido de la Carta, no es sino hasta la tercera parte del libro cuando ésta adquiere toda su dimensión, precisamente al compararla con la Ley $7 / 1985$, Reguladora de las Bases del Régimen Local, de 2 de abril, de práctica coetaneidad. No en vano, ambos textos legales son igualmente invocables y constitutivos de la normativa básica estatal sobre la materia, asegurando en todo el territorio del Estado un mínimo común de la autonomía garantizada a las Administraciones locales por la Constitución. Aún más, el autor se empeña en subrayar la superioridad de la Carta Europea sobre la Ley $7 / 1985$, tanto por su propia naturaleza de tratado internacional, como por su carácter de lex posterior.

RODRÍGuEZ ÁlvareZ recurre a su ya demostrado didactismo y a un estilo depurado para acometer lo que, a juicio de quien esto firma, es la parte central del trabajo. Con precisión, recorre la Carta Europea para presentamos los elementos que aportan un contenido no previsto, innovador, al principio de autonomía local tal como se recoge en la legislación española; aquellos otros que condicionan su interpretación, a los que llama ‘moduladores; y los que decididamente deben implicar, en opinión del autor, una derogación de su contenido.

Para no pecar de prolijidad, sólo comentaré que la legislación española de régimen local se adapta a los principios recogidos en la Carta sin que pueda hablarse de coincidencia.

Así, la Carta Europea de Autonomía Local reconoce el derecho de asociación de los entes locales, comprendida la cooperación internacional, confiriéndole, por tanto, un sentido más ambicioso; por otra parte, la literalidad de la Carta debería conducir a una atribución más amplia, en favor de los entes locales, de competencias sectoriales que comprendieran tanto los aspectos de gestión como los de ordenación; y, por último, el nivel de tutela jurisdiccional de la autonomía local resulta claramente contradictorio con las exigencias de la Carta Europea en la medida en que los entes locales españoles carecen de posibilidades de impugnación directa de las normas con fuerza de ley que lesionen su autonomía.

A nadie escapa que, cuando ya se van a cumplir veinte años del nacimiento de las primeras corporaciones democráticas, las insuficiencias del ordenamiento español con respecto a la garantía de la autonomía local son fruto de un complejo entramado de factores que hunden sus raíces en un pasado de relaciones interadministrativas separadas y centralizadas, caracterizado por la sumisión de los entes territoriales a la dirección política y el control del Estado, el mayor peso del ente local como organización prestadora de servicios que como estructura de representación democrática, o la pervivencia del inframunicipalismo. Algunos de estos rasgos todavía se dejan sentir y su superación pasa necesariamente por la conjunción de una serie de medidas que concluyan en la vigorización del rol que asumen las entidades locales a la luz de las prescripciones de la Carta Europea. El fortalecimiento de su dimensión política (a través del posible sometimiento de los Alcaldes a cuestiones de confianza, del reformamiento del control del Pleno sobre el equipo de gobierno e incluso de la elección directa de los Alcaldes), la superación de sempiternos problemas estructurales (el papel de las provincias, la supresión de municipios o el fortalecimiento de los mecanismos de agrupación y colaboración interadministrativa) o la atribución de un nivel de responsabilidad competencial y normativo que pueda corresponderse con el ideal de autonomía local, son algunas de las cuestiones sugeridas por la lectura del presente trabajo, elaborado por un privilegiado conocedor de la realidad local, tanto por su trayectoria profesional como por su presencia en los foros de discusión académica.

José M. Ruano de la FuEnTE Universidad Complutense de Madrid

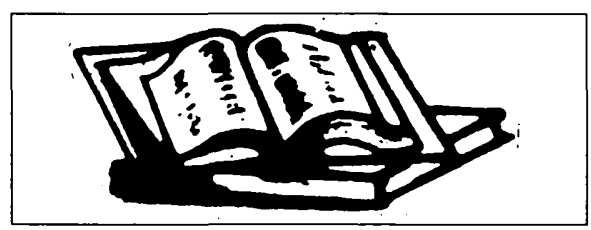

La Administración Española en Guerra

Ruano de la Fuente, José Manuel. Junta de Andalucía-Instituto Andaluz de Administración Pública, Sevilla, 1997. 302 págs.

Aunque la Ciencia de la Administración en los últimos años ha aportado luz sobre la estructura, funcionamiento y evolución de la Administración Pública en diferentes periodos de nuestra historia, resultaba llamativo que no se hubiera realizado un estudio suficientemente completo y detenido sobre la Administración española durante la Guerra Civil. 
De la etapa inmediatamente anterior a la misma disponemos de un excelente trabajo de José Manuel CANales; sobre la organización pública a partir de 1939 contamos con no pocos estudios y artículos, sobre todo desde finales de los años cincuenta. Restaba por hacer un análisis de la Administración espanola en guerra, y eso es lo que nos propone José Manuel RuaNo en esta publicación que da cuenta de su investigación doctoral.

El autor es un joven profesor de la Facultad de CC. Políticas y Sociología de la Universidad Complutense, especializado en Ciencia Política y de la Administración, siendo éste uno de los primeros trabajos que da al público. La formación y especialización interdisciplinares del autor se traslucen continuamente a lo largo de las más de trescientas páginas de su obra, superando las perspectivas tradicionales de la aprehensión de los hechos administrativos, demasiado dependientes del Derecho Administrativo, del Derecho Político y Constitucional, e incluso de la Historia.

La finalidad de su análisis es mostrar la estructura orgánica y el funcionamiento de la Administración Central del Estado en el contexto de convulsión política que supuso nuestra contienda civil. Para ello se fija como objeto de estudio las dos Administraciones centrales coetáneas enfrentadas, la republicana y la nacionalista. El autor limita, no obstante, dicho objeto a las Administraciones centrales civiles de cada bando, aunque eventualmente contempla la Administración militar y las Administraciones territoriales, regionales y locales, en la medida que éstas y aquélla están conectadas a la Administración del Estado.

La exposición se realiza en siete capítulos. En el primero presenta los planteamientos generales y objetivos del trabajo de la manera usual en las investigaciones doctorales, reseñando el objeto, la metodología, las fuentes, y el encuadramiento cientíico.
En el segundo se nos presentan datos sobre la Administración republicana en tiempos de paz, abundando en la situación política y social, la Constitución republicana, las relaciones entre la Jefatura del Estado y el Gobiemo, la estructura departamental de la Administración civil del Estado, la Administración territorial, y los intentos de reforma de la función pública. Estos datos, lejos de ser redundantes por conocidos en gran medida por la doctrina, aportan un basamento sólido desde el que comprender el marco político-social e institucional en que toma vida el objeto de estudio propuesto.

Los capítulos tercero y cuarto se centran en las dos Administraciones en guerra desde la perspectiva de las grandes mutaciones del complejo institucional del Estado, y mostrando especial preocupación por los cambios de gobierno, su incidencia en la estructura orgánica y los medidas tendentes a la depuración del funcionariado. Es un hallazgo del prof. Ruavo la obtención de categorías que con independencia del diferente matiz ideológico y organizativo de ambas Administraciones, permitan realizar comparaciones plausibles.

Lo mismo podemos decir respecto a los capítulos cinco y seis (que versan respectivamente sobre la organización administrativa básica, durante la Guerra Civil, del régimen republicano y del bando nacionalista). Se inclina de nuevo el autor a realizar una presentación basada en bloques más o menos homogéneos de contenido suceptibles de comparación. Esa fragmentación temática sigue el esquema siguiente: la Administración de los servicios de soberanía -incluyendo aquí la Presidencia del Consejo de Ministros en tanto departamento ministerial, las relaciones exteriores, los servicios de propaganda, los servicios de justicia y la Administración de la guerra-; la Administración de la políica económica y financiera -integra la Administración de industria, Comercio, hacienda, agricultura e infraestructuras-; la Administración social -n que se insertan la Administración de educa- ción, cultura, sanidad y asistencia social, la Administración laboral y de previsión-; así como los intentos de reforma administrativa. Además en el capítulo sexto, referido a la estructura interna de la organización administrativa nacionalista, se aporta un primer análisis de la consolidación de la Administración del bando insurgente en los primeros años de la postguerra, para ello se detiene el autor en las sucesivas remodelaciones de los gabinetes de postguerra, así como en la evolución orgánica y funcional del nuevo Estado.

El capítulo séptimo enuncia las conclusiones.

De los resultados obtenidos en esta investigación podrían destacarse los siguientes:

1. Respecto a la Administración republicana. Con el estallido de la contienda se evidenció la falta de adecuación de la organización administrativa a su entorno sociopolitico. A la tradicional rigidez de la Administración se añadió la exacerbación de diferentes fracturas del sistema político (ideológicas, territoriales, religiosas, económicas, culturales...) que contrastaban con la debilidad del orden constitucional. Dichas fracturas incidieron decisivamente en la degradación progresiva del aparato organizativo. Además, los diferentes gobiemos republicanos -de Giral, Largo Caballero y Negrín- adoptaron políticas incoherentes entre sí. Si a ello añadimos a partir de determinado momento las interferencias de los partidos políticos y los sindicatos en la Administración, junto a la pervivencia de los diferentes entes temitoriales mediatizando las comunicaciones y las relaciones de poder, nos encontramos con un aparato administrativo desordenado $y$, en algunos momentos, en proceso de descomposición. 
2. Respecto a la Administración nacionalista. Durante la Guerra Civil adquirió las notas del totalitarismo fascista, que hay que unir a los principios de la derecha tradicional, de la iglesia católica y del militarismo decimonónico, para comprender su carácter tendente a la centralización y la disciplina. De manera que la Administración nacionalista no admite ni oposición ideológica ni otras Administraciones competidoras, rechazando la descentralización territorial. Con estos caracteres, dicha Administración aparecía más adaptada al contexto bélico, y no pocos de ellos lograron fijarse en la Administración postbélica, así el carácter totalitario del régimen político, la militanización de los servicios públicos, la depuración del funcionariado, la propaganda y censura, control policial de la población, etc.

3. Respecto a ambas Administraciones. Las dos Administraciones intentan adaptarse al entorno bélico. Aunque no lo consigan al mismo tiempo -la Administración rebelde toma ventaja sobre la republicana-, puede decirse que a partir de mayo de 1937 la estructura y funcionamiento de las dos Administraciones es similar: basada en la depuración del funcionariado, concentración del poder en el Jefe del Gobiemo, generalización de los servicios de propaganda, militarización de sectores administrativos relacionados con la guerra, intervención económica y social, depuración del personal, la influencia del partido único en el caso nacionalista y del PCE en el caso republicano, entre otros factores.

Para concluir cabe decir que nos encontramos ante un trabajo novedoso sobre la Guerra Civil, aseveración ésta que habida cuenta la innumerable bibliografia existente sobre la misma no puede dejar de sorprender. El profesor Ruavo ha sabido explotar las exiguas fuentes documentales existentes sobre su objeto de estudio y, complementándolas con una ingente bibliografía y documentación -que abarca desde periódicos de la época a no pocas obras de carácter general-, ha conseguido una obra sólida y rigurosa, que ha de interesar por igual al historiador y al politólogo.

Jorge CRESPO GONZÁLEZ Universidad Complutense de Madrid

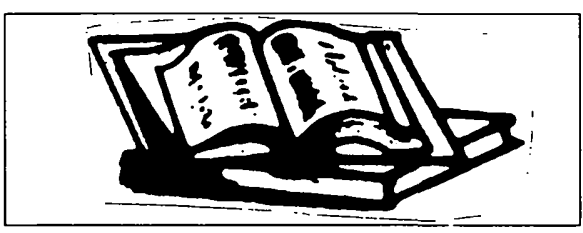

Modelos de función pública comparada

Ministerio de Administraciones Públicas / Presidencia del Gobierno. Primera edición: junio 1997. Equipo de redacción ${ }^{1}$ dirigido y coordinado por Manuel MARTínez BaRGueÑo.

Cuando los tiempos son de cambios y la marcha del género humano desde la tribu del universo se acelera, es indispensable conocer qué está ocurriendo en el ámbito en el que nos movemos y en nuestro entorno. Nuestro ámbito es el de la Función Pública; nuestro entorno, una serie de Estados que nos resultan próximos por geografía, historia y tradiciones; con los cuales, en esa larga marcha, habremos de coincidir en una unidad.

Resulta por ello loable el esfuerzo que, realizado como un "plusn a su actividad profesional, un grupo de funcionarios vinculados durante años a los temas de la Función Pública, ha realizado para indagar el estado de la misma cuestión en otros países. Es un tópico decir que

\footnotetext{
${ }^{1}$ Santiago Asevsio Merino, S.G. Adjunto de Becas y Ayudas al Estudio, MEC. Manuel Mastitez Barguevo, S.G. de Gestión de Funcionarios, MAP. Pilar Fabrecat Ronie Ro, Vocal Asesor Subsecretaría, MEC. Alfonso Morevo Gounz, S.G. de Planificación y Selección de Recursos Humanos, MAP. Javier Montero y CASAdO de AurzZu, Administrador Principal de la Comisión Europea.
}

el mundo es cada vez más pequeño; que las fronteras de los Estados modemos y sus caracteres diferenciales se difuminan progresivamente; que un ciudadano de cualquier país, en el curso de un mismo día, puede tener necesidad de reclamar servicios de más de una de las, todavía, Administraciones nacionales; que esos servicios se van homogeneizando y que la forma de prestarlos, las organizaciones que lo realizan y las erso as que los desarrollan están también en el mismo camino de homogeneización; y cuando, ya ahora, los ciudadanos de un Estado pueden incorporarse a la Función Pública de otro.

Han seleccionado cinco Estados: Alemania, Francia, Italia, Reino Unido, Suecia y, además, la Comisión Europea. Con el criterio de recoger la legislación positiva vigente (a la que se añaden en algunos casos los inmediatos antecedentes) y una sistemática homogénea en la que se van destacando las cuestiones esenciales, se enuncian para cada país las características que describen el perfil de su Función Pública. Algunos de ellos responden a la misma tradición latino-francesa que la Administración española; otros han desarrollado su historia por cauces distintos. Existen, sin embargo, algunos rasgos comunes que seguramente conviene poner de manifiesto.

Se constata en primer lugar que la situación de todos, en este momento, es de revisión y cambio en los perfiles definitorios de su Función Pública. Diríase que existe una general insatisfacción con el sistema jurídico existente para organizar la Función Pública en cada Estado, sin que de las modificaciones que se prevén en cada uno pueda deducirse la aparición de líneas convergentes. $\mathrm{Ni}$ siquiera lo que parece ser argumento supremo, la reducción de efectivos, es criterio general en los países estudiados. Aunque el período intercensal no es homogéneo para los cinco Estados, Alemania y Suecia disminuyen los recursos humanos de su sector público (de 100 en 1993 a 86,77 en 1995 para el primero y 
de 100 en 1985 a 99,78 en 1993 para el segundo), mientras que Francia (entre 1980 y 1994), Italia (entre 1985 y 1993) y Reino Unido (entre 1990 y 1995), los incrementan en porcentajes del $1,83,1,78$ y 1,31 respectivamente; pero también resulta que, a la vez que disminuyen los efectivos en uno de los componentes del sector público, aumentan en otro; con lo que el peso sobre la economía del país se mantiene.

Los cambios parecen tender más a modificaciones en la naturaleza de la relación jurídica. El más espectacular, por lo que supone de giro copernicano, es el de Italia, que a partir de la Ley 421, de 23 de octubre 1992, ha llevado ésta a una relación de Derecho privado; al menos para una parte de su Función Pública. Surgen aquí dos reflexiones: la primera, que el invento no es nuevo: ya se ensayó en la España de la Regencia (la Ley de Presupuestos de 1835 trata de reducir al mínimo los empleados de nombramiento real -funcionarios stricto sensu-, de modo que .... en los gobiernos civiles sólo se tengan el secretario, oficial primero y oficial segundo, y que los de- más los nombre el gobernador civil ... siendo además amovibles a su voluntad. Lo recoge el Profesor Nieto García en la pág. 374 de Los primeros pasos del Estado constitucional. La segunda, de si tamaña novedad, en Italia, no responderá a lo que Indro MONTANELU escribe en el Epílogo de su Historia de Italia (19951997): Quizás sigamos siendo como somos: un conglomerado empeñado en discutir, con grandes palabras, las grandes reformas.... Es decir, configurar legalmente la distinción entre funcionario y empleado: aquél desarrollará las funciones más directamente relacionadas con las funciones esenciales del Estado; éste, las más alejadas de esta consideración.

Sorprenden algunos de los datos que aportan: la continuidad de la organización en el Reino Unido (asumen que existe desde 1853), así como la condición de servidores de la Coronan que ostentan los funcionarios. (En España el concepto de -Oficial Real. se perdió a raíz de la Constitución de 1812); la utilización de la entrevista en el proceso de selección... (pp. 74 y 75). O bien, la simplicidad del sistema retributivo francés (p. 41). La or- denación en áreas de la Administración alemana y la exigencia de titulaciones académicas concordantes, así como el largo período de prácticas y la figura del funcionario a título de prueba; o el esquema de ecarrera profesional, que se diría del más puro corte napoleónico (pp. 19 y 20). O sea que en Suecia exista una desigualdad en las retribuciones por causa de sexo (p. 105).

En definitiva, un meritorio trabajo, que sorprendería no tuviera continuidad. O más exactamente, en tiempos de cambios, diríase que resulta imprescindible tener información y aún más importante, mantenerla al día, por su misma condición de cambiante; lo que haría aconsejable la institucionalización de un equipo que, como parte de sus funciones principales, tuviera asignada la de conocer lo que ocurre en nuestro ámbito y en nuestro entorno.

Ricardo GONZÁlEZ ANTÓN Cuerpo Superior de Administradores Civiles del Estado 
